\title{
Fluência Tecnológico-Pedagógica na Formação Inicial de Professores Mediada por Tecnologias Educacionais em Rede
}

\author{
Iris Cristina Datsch Toebe ${ }^{1}$, Elena Maria Mallmann², Sabrina Bageti,
} Adriana Pereira ${ }^{4}$

${ }^{1}$ Doutoranda em Informática na Educação - UFRGS; iristoebe@gmail.com

${ }^{2}$ Doutora em Educação, Departamento de Administração Escolar, Programa de PósGraduação em Educação da UFSM; elena.ufsm@gmail.com

${ }^{3}$ Doutoranda em Educação, pelo Programa de Pós-Graduação em Educação da UFSM; sabribagetti@gmail.com

${ }^{3}$ Dr. ${ }^{\text {a }}$ Prof. ${ }^{\text {a }}$ Departamento de Tecnologia da Informação; UFSM-FW; adriana.pereira@ufsm.br

\begin{abstract}
The focus of this article is to present results of a research on the integration of educational technologies in the Pedagogical Projects of the Pedagogical Courses (day, night and distance) of the Education Center (CE) of the Federal University of Santa Maria (UFSM). For this, the work was centered within the qualitative plans of Moraes and Galiazzi's (2006) discursive textual analysis. Conclusively, we highlight the promotion of the development of technological and pedagogical fluency coupled with the public policies of undergraduate courses, to enhance teaching and learning mediated by network technologies. The integration of networking technologies in initial teacher training promotes the convergence between face and distance modalities by deploying multipliers for the construction of curricular knowledge in both higher education and basic education.
\end{abstract}

RESUMO: O foco deste artigo é apresentar resultados de uma pesquisa sobre a integração das tecnologias educacionais em rede nos Projetos Pedagógicos dos Cursos (PPC) de Licenciaturas em Pedagogia (diurno, noturno e a distância) do Centro de Educação (CE) da Universidade Federal de Santa Maria (UFSM). Para tanto, o trabalho centrou-se dentro dos planos qualitativos da análise de textual discursiva de Moraes e Galiazzi (2006). Conclusivamente, destaca-se as orientação de fomento ao desenvolvimento da fluência tecnológico-pedagógica acoplada às políticas públicas dos cursos de licenciatura, para potencializar ensino-aprendizagem mediado pelas tecnologias em rede. A integração das tecnologias em rede na formação inicial de professores promove a convergência entre as modalidades presencial e a distância desdobrando multiplicadores para a construção de conhecimentos curriculares tanto no ensino superior quanto na educação básica. 
VII Congresso Brasileiro de Informática na Educação (CBIE 2018)

Anais dos Workshops do VII Congresso Brasileiro de Informática na Educação (WCBIE 2018)

\section{Introdução}

O processo ensino-aprendizagem na cultura contemporânea mediada por tecnologias em rede gera expansão e democratização de acesso à escolaridade (no caso deste estudo, à formação inicial de professores compreendida como aquele que acontece nos cursos universitários de graduação). As mídias digitais e, particularmente, as tecnologias educacionais em rede flexibilizam as práticas escolares, tendo em vista que possibilitam o desenvolvimento de atividades curriculares e extracurriculares em tempos e espaços que ampliam o conceito de sala de aula. Ademais, através da interatividade, potencializam interação em rede e isso tende a gerar construção colaborativa de saberes.

Nesse contexto, parte-se do princípio que para mediar situações de ensinoaprendizagem em rede na formação de professores, é fundamental que os professores formadores estejam preparados e qualificados. Implica, pois, reflexos imediatos na prática profissional dos estudantes e egressos dos cursos de licenciaturas.

Por isso, defende-se a importância de se trabalhar com capacitações sustentadas nas potencialidades hipermidiáticas das tecnologias em rede coligando tecnologia e pedagogia, na prática dos professores tanto no ensino superior quanto na educação básica. Os Parâmetros Curriculares Nacionais da Educação, em seus objetivos para o ensino fundamental, orientam os docentes para práticas que oportunizem a capacidade de saber utilizar diferentes fontes de informação e recursos tecnológicos para adquirir e construir conhecimentos (BRASIL, 1997).

Nessa perspectiva de integração, a Universidade Federal de Santa Maria (UFSM) disponibiliza a plataforma Moodle como Ambiente Virtual de Ensino-Aprendizagem (AVEA). É uma ferramenta de apoio tanto aos cursos presenciais quanto espaço virtual das disciplinas dos cursos à distância. Centrando o foco deste estudo, que são os cursos de licenciaturas em Pedagogia (modalidades presencial e a distância) do Centro de Educação (CE) da UFSM, entende-se que há necessidade de ampliar gradativamente a integração das tecnologias educacionais em rede na formação docente. Diante disso, os desafios da integração do Moodle são inquietantes, uma vez que as políticas nacionais e institucionais induzem integração de mídias diversas, mas nem sempre a logística e as práticas concretizam as proposições legais e teóricas. Também, os enunciados dos textos legislativos permitem um leque muito grande de interpretações e juízos quanto à aplicabilidade das parametrizações. Assim, nos Projetos Pedagógicos de Cursos (PPC) a menção às tecnologias adquire, muitas vezes, um tom descritivo ou mesmo prescritivo.

Assim sendo, o trabalho investigativo permitiu diagnosticar as possibilidades de integração das tecnologias educacionais em rede previstas nos PPC para implementação, nos cursos de Licenciatura em Pedagogia do CE da UFSM e analisar as políticas públicas educacionais vigentes para formação inicial de professores.

\section{Integração das tecnologias educacionais em rede na formação de professores para desenvolvimento de fluência tecnológico-pedagógica}

A integração das tecnologias educacionais em rede oportuniza práticas escolares em meio a possibilidades de inovações pedagógico-tecnológicas na formação de professores, com perspectiva de potencializar o processo ensino-aprendizagem mediado 
VII Congresso Brasileiro de Informática na Educação (CBIE 2018)

Anais dos Workshops do VII Congresso Brasileiro de Informática na Educação (WCBIE 2018)

por atividades no Moodle institucional. Entretanto, para integrar este software como ferramenta de apoio no ensino presencial ou ferramenta mediadora na educação a distância, requer o desenvolvimento de aptidões que encontram-se relacionadas a fluência tecnológico-pedagógica. Isso porque, o professor precisa aprimorar sua fluência para ter condições de ampliar suas possibilidades de planejamento e fortalecer seus subsídios teórico-práticos para percorrer pelas ferramentas do Moodle, de modo que venha inovar nas práticas docentes. Desse modo, tem-se inúmeras possibilidades de explorar as ferramentas hipermidiáticas resultando em alternativas viáveis para inovação tecnológico-pedagógica.

Para Mallmann, Schneider e Mazzardo (2013), a fluência reúne conhecimentos e práticas, teoria e ações, é saber fazer o melhor em cada situação, com cada recurso, sendo que não acontece no improviso, é resultado de formação. Conforme as autoras, ela possibilita a articulação do processo ensino-aprendizagem, indica maior nível de aprendizagem, a qual responde pela mudança de comportamento com obtenção de êxito em um saber fazer. Desse modo, envolve não apenas saber como usar ferramentas tecnológicas, mas também saber como construir coisas significativas com essas ferramentas na medida em que situações problemáticas precisam ser resolvidas (MALLMANN, SCHNEIDER E MAZZARDO, 2013, p.04)

Por isso, e fundamental que a fluência seja desenvolvida tanto no plano tecnológico quanto no pedagógico, pois trata-se de compreender os processos educativos orientados por concepções teóricas e não centradas unicamente em fundamentos metodológicos ou de ordem técnico-prática. Assim, sustenta-se o argumento a respeito da necessária congruência entre o desenvolvimento da fluência numa matriz tecnológicopedagógica. Fluência tecnológico-pedagógica não se restringe ao saber-fazer técnico, mas está consoante ao disposto nos fundamentos epistemológicos, na organização curricular de um curso, nos aspectos sociais, éticos, políticos e ontológicos dos envolvidos nos processos, nas condições operativas e logísticas permitidas pela infraestrutura do contexto. Por esse motivo, fluência tecnológico-pedagógica é um processo longo e contínuo que caminha em convergência tendo em vista que todo processo educativo é intencional e metódico.

Aprimorar a fluência tecnológico-pedagógica demanda entendimento de que se trata de um processo epistemológico e operacional longo e contínuo. Desse modo, Kafai et al (1999), enfatizam que para ser fluente em tecnologias é necessário desenvolver habilidades contemporâneas, conceitos fundamentais e capacidades intelectuais. Assim, sob a perspectiva teórica eleita, ao agregar os princípios da tecnologia e da pedagogia podemos dizer que é desenvolvida em três instâncias: a) a fluência técnica é o conhecimento que o professor e o estudante devem possuir, por exemplo, ao ligar/desligar o computador, acessar o ambiente Moodle (plataforma institucional na UFSM); b) a fluência prática está relacionada com ação mediadora e a capacidade de explorar a mídia a seu favor, potencializando a capacidade de resolver dificuldades inesperadas e indesejadas; c) a fluência emancipatória é construída e aprimorada a partir do desenvolvimento das duas anteriores, mas na dimensão do compartilhamento colaborativo de conhecimento produzido.

Portanto, a construção da fluência, por parte dos estudantes e professores, permite a interação e a interatividade, através do planejamento e implementação de recursos e atividades de estudo mediadas pelo AVEA. Em se tratando destas tecnologias, a todo 
VII Congresso Brasileiro de Informática na Educação (CBIE 2018)

Anais dos Workshops do VII Congresso Brasileiro de Informática na Educação (WCBIE 2018)

instante na cultura midiática contemporânea, surgem novas possibilidades de integração no âmbito escolar cabendo aos professores e estudantes desdobrá-las e desenvolvê-las no processo ensino-aprendizagem.

O Moodle institucional proporciona meios de viabilizar a comunicação, a interação e o diálogo-problematizador. Assim, contribui para o processo ensinoaprendizagem e para o fortalecimento da produção colaborativa entre estudante-estudante e estudante-professor, oportunizando que o estudante construa sua própria autonomia nesse processo. Além disso, possibilita desenvolver inovações na prática pedagógica, em todas as áreas, adequando tecnologias com as necessidades do currículo e a organização escolar, visto que, a "integração é a junção de partes que trabalham isoladamente, formando um conjunto que trabalha como um todo" (SONEGO, 2014, p. 35).

Todavia, a integração das tecnologias educacionais em rede e a convergência entre as modalidades proporcionam flexibilidade da hipermídia nos materiais que apresentam informações e conhecimentos em diversas linguagens em um mesmo recurso (MARCHIONINI, 1988). A interatividade torna a leitura menos linear oferecendo novas possibilidades de aprendizado com as diversas tecnologias (textos, vídeos, áudios e imagens). Várias mídias (sons, textos, imagens) impulsionam o planejamento, implementação e realização de atividades mediadas pelo Moodle que permitem a navegação e exploração destas, fortalecendo o processo ensino-aprendizagem dos estudantes em ambas as modalidades educacionais. Para aprofundamento da integração das tecnologias precisa perpassar pela construção dos projetos político-pedagógicos dos cursos de licenciaturas amparados nas orientações eminentes das políticas públicas. É claro, contextualizá-las de acordo com as demandas e o perfil dos grupos.

Assim, considera-se relevante que as ferramentas tecnológicas proporcionem a criatividade, a simulação de situações problemas que demandam do professor respostas imediatas (OLIVEIRA, SANTOS, FONTES, 2016). Nesse sentido, a formação inicial deve proporcionar distintas ocasiões para integrar as tecnologias educacionais em rede a fim de complementar lacunas que surgem nas práticas docentes minimizando distanciamentos entre teoria e prática.

\section{Políticas públicas para construção dos projetos pedagógicos dos cursos de licenciatura em pedagogia}

Para integração das tecnologias educacionais em rede, as políticas públicas desempenham um papel fundamental nos cursos de formação inicial de professores. Uma vez que, orientam o acesso e o aperfeiçoamento tecnológico-pedagógico dos professores para desenvolvimento de práticas escolares. Segundo Souza (2016, p.86), estudar e conhecer as políticas públicas gera, entre outros, o conhecimento de como "são operadas as relações entre o Estado e a Sociedade na luta pelo reconhecimento da educação como direito, nos desafios da sua oferta e organização e nos conflitos decorrentes da busca por qualidade".

Para tanto, deve-se ter atenção sobre os impactos de tais orientações e verificar como são elas são implementadas e efetivadas nas instituições. Ao considerar que no atual contexto das políticas públicas, evidencia-se uma demanda crescente do número de documentos que fomentam expansão desta modalidade de ensino. Scheibe e Aguiar 
VII Congresso Brasileiro de Informática na Educação (CBIE 2018)

Anais dos Workshops do VII Congresso Brasileiro de Informática na Educação (WCBIE 2018)

(1999, p. 221) destacam que no ensino superior o processo de regulamentação é contínuo e "se efetiva de modo bastante fragmentário, por meio de múltiplos instrumentos legais, como leis ordinárias, decretos, emendas constitucionais e mesmo medidas provisórias".

Entendemos que nesse processo, faz-se necessário discutir não somente a expanção do ensino, mas ir além, primando pela qualidade do ensino e a gestão democrática (SOUZA, 2016). Nesta perspectiva, a fluência tecnológico-pedagógica torna-se primordial para apresentar propostas de inovações metodológicas, projetos de aperfeiçoamento e capacitação docente.

As atuais políticas públicas educacionais, por meio das Diretrizes Curriculares Nacionais para a formação de professores (BRASIL, 2015) apresentam ações que guardam intrínsecas conexões com a utilização das tecnologias educacionais em rede, articulando posições referentes à formação de professores em busca de uma identidade formativa e de qualidade. Segundo o documento:

No exercício da docência, a ação do profissional do magistério da educação básica é permeada por dimensões técnicas, políticas, éticas e estéticas por meio de sólida formação, envolvendo o domínio e manejo de conteúdos e metodologias, diversas linguagens, tecnologias e inovações, contribuindo para ampliar a visão e a atuação desse profissional (BRASIL. 2015, p.03).

No mesmo documento, identifica-se também a indução de uma base comum nacional, que orienta a formação de profissionais, pautada pela concepção de educação como processo emancipatório e permanente, que saiba reconhecer as especificidades de seu trabalho pedagógico, promovendo articulações teórico-práticas por meio de:

[...] IV - dinâmicas pedagógicas que contribuam para o exercício profissional e o desenvolvimento do profissional do magistério por meio de visão ampla do processo formativo [...] possibilitando as condições para o exercício do pensamento crítico, a resolução de problemas, o trabalho coletivo e interdisciplinar, a criatividade, a inovação, a liderança e a autonomia;

[...] VI - uso competente das Tecnologias de Informação e Comunicação (TIC) para o aprimoramento da prática pedagógica e a ampliação da formação cultural dos(das) professores(as) e estudantes;

[...] VIII - desenvolvimento, execução, acompanhamento e avaliação de projetos educacionais, incluindo o uso de tecnologias educacionais e diferentes recursos e estratégias didático-pedagógicas; (BRASIL. 2015, p.06).

Ao encontro destes apontamentos, temos a resolução do Conselho Nacional de Educação que aponta ser fundamental que o docente que atuará na Educação Básica, tenha a capacidade de saber utilizar assim como relacionar as diversas "linguagens dos meios de comunicação à educação, nos processos didático-pedagógicos, demonstrando domínio das tecnologias de informação e comunicação". (RESOLUÇÃO CNE/CP No 1 , de 15 de maio de 2006).

Deste modo, percebe-se que a integração das tecnologias em rede apresenta-se como uma alternativa de inovação, exercício de reflexão, (re) utilização crítica e criativa de conteúdos específicos de cada uma das áreas do conhecimento, envolvidos na construção dos PPC de licenciatura em Pedagogia. 
VII Congresso Brasileiro de Informática na Educação (CBIE 2018)

Anais dos Workshops do VII Congresso Brasileiro de Informática na Educação (WCBIE 2018)

Contemplar as tecnologias na elaboração dos PPC é orientado e previsto em documentos oficiais como o Edital $n^{\circ}$ 015/2010/CAPES/DED (BRASIL, 2010). Na época o referido edital já contemplava no horizonte a tendência de movimentos internacionais de fomento à educação aberta, com atenção redobrada aos eixos qualificadores do ensino universitário brasileiro:

\begin{abstract}
amplitude de atendimento e primazia do uso das tecnologias de comunicação e informação. A concepção da proposta deve favorecer a institucionalização de práticas de ensino-aprendizagem abertas, utilizando tecnologias de informação e comunicação, que favoreçam o desenvolvimento acadêmico em dois eixos: a autonomia de aprendizado nos estudantes e a melhoria da qualidade no ensino de graduação (BRASIL, 2010, p.03)
\end{abstract}

Pode-se perceber que as orientações dispostas nas políticas públicas para formação de professores, projetam o desenvolvimento de profissionais capacitados para "trabalhar, em espaços escolares e não escolares, na promoção da aprendizagem de sujeitos em diferentes fases do desenvolvimento humano, em diversos níveis e modalidades do processo educativo." (Resolução CNE/CP No 1 , de 15 de maio de 2006). Assim, nestes cursos, os futuros professores estão suscetíveis à formação reflexiva geradora de competências para resolução de problemas nas situações mais adversas do âmbito educacional (Pereira, 2006). Nessa perspectiva, a fluência tecnológicopedagógica apresenta-se como princípio basilar do trabalho docente independente do nível ou modalidade.

Destaca-se assim, a importância do desenvolvimento e valorização profissional para que a integração das tecnologias educacionais ocorra de modo a potencializar o ensino-aprendizagem tanto na educação básica quanto no ensino superior. Chaves e Setzer (1988) afirmam, em seus estudos, que a escola atualmente deve desmistificar as ferramentas computacionais mostrando à criança o seu potencial e as suas limitações. Ao encontro destes entendimentos Lévy (1998), afirma que na era da informação, as crianças aprendem a ler e escrever utilizando editores de texto, sabem produzir sons e imagens com os computadores transformando continuamente os conteúdos de ensinoaprendizagem. Ações que demandam, segundo o autor, implementar um "novo estilo de pedagogia que favoreça, ao mesmo tempo, o ensino-aprendizagem personalizado e cooperativo em rede" (LÉVY, 1998, p.02).

Neste sentido, ressalta-se que a integração das tecnologias com vistas ao desenvolvimento da fluência tecnológico-pedagógica potencializa a formação de profissionais capacitados para promoverem práticas pedagógicas, que estimulem o desenvolvimento do processo ensino-aprendizagem de maneira dinâmica e inovadora. Nesse seguimento, às propostas políticas de formação de professores vêm desenhando traços gerais para a melhoria da qualidade dos cursos de licenciatura, mais especificamente nos cursos de Pedagogia. No entanto, essas melhorias requerem uma maior articulação entre as políticas públicas educacionais vigentes e seus respectivos PPC, emergindo para ações de reformulações.

\title{
4. Estratégias metodológicas e resultados do estudo
}


VII Congresso Brasileiro de Informática na Educação (CBIE 2018)

Anais dos Workshops do VII Congresso Brasileiro de Informática na Educação (WCBIE 2018)

Metodologicamente o trabalho centrou-se dentro dos planos qualitativos por meio de uma análise Textual Discursiva com base nos estudos de Moraes (2003) e Moraes e Galiazzi, (2006). Ao total, foram selecionados e separados em unidades de significado 26 documentos entre políticas públicas e parâmetros de orientação. Estas unidades por si mesmas geraram "outros conjuntos de unidades oriundas da interlocução empírica, da interlocução teórica e das interpretações feitas pelo pesquisador" (MORAES e GALIAZZI, 2006, p.02).

Foram analisados os respectivos documentos, utilizando como parâmetro as políticas públicas educacionais vigentes. A partir de estudo do corpus textual composto pelo conjunto de leis, decretos, resoluções, editais e normativas pôde-se estabelecer como evidência investigativa que a integração das tecnologias educacionais em rede está prevista tangencialmente em seus currículos.

\section{Considerações finais}

Com base neste estudo, foi possível compreender a importância da coerência entre as políticas públicas e os PPC de graduação em licenciaturas em Pedagogia. O fomento e a indução política pode orientar o desenvolvimento de fluência tecnológico-pedagógica na docência incrementando interação, colaboração e autonomia no processo ensinoaprendizagem.

Desse modo, considera-se basilar, a integração das tecnologias educacionais em rede na formação inicial de professores com potencial gerador de convergência entre as modalidades educacionais. Assim, abre caminhos para práticas de (re)planejamentos de ensino, podendo estes serem implementados em ambas as modalidades, agregando diversidade para a aquisição de novos conhecimentos em torno dos conteúdos curriculares. Ademais, possibilita a produção de materiais hipermidiáticos, mediados por tecnologias em rede com características de interação e a interatividade, propiciando a produção colaborativa e o compartilhamento de conhecimento. A integração das tecnologias educacionais contemporâneas e convergência entre as modalidades na UFSM ampliam as possibilidades de ensinar e aprender, proporcionando transcorrer pelo desdobramento da fluência tecnológico-pedagógica com os envolvidos (professoresestudantes) nos processos ensino-aprendizagem, tanto presenciais quanto a distância.

Portanto, admite-se que é imperioso que os professores amparem-se nas políticas públicas educacionais com intuito de obter orientações nas capacitações visando o desenvolvimento da fluência tecnológico-pedagógica, obtendo subsídios teórico-práticos para mediar atividades por meio das tecnologias educacionais em rede. Além disto, os PPC dos cursos de licenciatura em Pedagogia do CE/UFSM evidenciam a capacitação em relação às tecnologias educacionais para a progressão das ações docentes.

Destarte, que o desenvolvimento da fluência tecnológico-pedagógica e a integração das tecnologias podem promover inovações didático-metodológicas no processo ensino-aprendizagem. Isso é tanto da ordem da pedagógica (concepções e valores éticos, políticos e estéticos) quanto tecnológica (artefatos e procedimentos operacionais). Infraestrutura adequada com alternativas viáveis para revisar práticas e conteúdos na formação inicial de professores é condicionante de movimentos produtivo- 
VII Congresso Brasileiro de Informática na Educação (CBIE 2018)

Anais dos Workshops do VII Congresso Brasileiro de Informática na Educação (WCBIE 2018)

colaborativos que possam compatibilizar diferentes perspectivas didático-metodológicas, currículos e princípios epistemológicos.

Desse modo, a compreensão de atividades curriculares mediadas por tecnologias educacionais em rede na formação de professores não se limita a uma discussão de conteúdos básicos ou conteúdos de aprofundamento ou parte diversificada. Construção de fluência tecnológico-pedagógica perpassa todos esses eixos tanto no que se refere ao exercício da docência quanto da gestão, para as quais um profissional formado em Pedagogia está habilitado nos termos da legislação educacional vigente.

Nesse cenário, está evidente que os movimentos sociais e econômicos mediados por tecnologias em rede não geram impactos imediatos nos modos de produção de conhecimento nem na educação básica e nem ensino superior. Torna-se imperativo compor textos legais tanto das políticas públicas quanto PPC que sejam autênticos movimentos de construção da inovação cunhada em princípios da comunicação, colaboração e autonomia para o desenvolvimento psíquico intelectual enquanto conhecimento científico, tecnológico, sociocultural.

\section{Referências}

BRASIL, M. E. C. Ministério da Educação. Conselho Nacional de Educação. Diretrizes Curriculares Nacionais para a formação inicial em nível superior (cursos de licenciatura, cursos de formação pedagógica para graduados e cursos de segunda licenciatura) e para a formação continuada. Resolução $C N E / C P$ n. 02/2015, de $1^{o}$ de julho de 2015.

BRASIL, M. E. C. Ministério da Educação. Conselho Nacional de Educação. Coordenação de Aperfeiçoamento de Pessoal de Nível Superior. Edital $N^{o}$ 15_Capes_Fomento ao uso das TIC. Disponível em:<http://www.capes.gov.br/educacao-a-distancia/editais/fomento-as-tics >.

BRASIL, M. E. C. Ministério da Educação. Conselho Nacional de Educação. Resolução CNE/CP $N^{o} 1$, de 15 de maio de 2006. Disponível em: <http://portal.mec.gov.br/cne/arquivos/pdf/rcp01_06.pdf >.

BRASIL, M. E. C. Ministério da Educação. Parâmetros Curriculares Nacionais introdução aos parâmetros curriculares nacionais / Secretaria de Educação Fundamental - Brasília: MEC/SEF, 1997.126p.

CHAVES, E. O. C.; SETZER, V. W. O uso de computadores em escolas: fundamentos e críticas. São Paulo: Scipione, 1988.

KAFAI, Y. et al. Being fluent with information technology, 1999. Disponível em: $<$ http://www.nap.edu/catalog/6482.html\&gt >.

LÉVY, P. As tecnologias da inteligência: o futuro do pensamento na era da informática. Rio de Janeiro: Editora 34, 1998. 
VII Congresso Brasileiro de Informática na Educação (CBIE 2018)

Anais dos Workshops do VII Congresso Brasileiro de Informática na Educação (WCBIE 2018)

LÉVY, P. Educação e cybercultura. Porto Alegre, março de, 1998.

MALLMANN, E. M. SCHNEIDER, D. DA R. MAZZARDO M. D. Fluência Tecnológico-Pedagógica (FTP) dos Tutores. Revista Novas Tecnologias na Educação V. $11 \mathrm{~N}^{\circ}$ 3. CINTED- UFRGS, Dezembro, 2013.

MARCHIONINI, G. Hypermedia and learning: feedom and chaos, Educational Technology, 28(11), 8- 12, November. In: REZENDE, F; COLA, C. dos. S. D. Hipermídia na Educação: Flexibilidade Cognitiva, Interdisciplinaridade e Complexidade. Ensaio Pesquisa em Educação em Ciências, vol. 6, n. 2, 2004, p. 1-11. Universidade Federal de Minas Gerais, Minas Gerais, Brasil. Disponível em: < http://www.portal.fae.ufmg.br/seer/index.php/ensaio/article/view/81/128 >.

MORAES, R; GALIAZZI, M. C. Análise textual discursiva: processo construído de múltiplas faces. Ciência \& Educação, v.12, n.1, p.117-128, 2006.

OLIVEIRA, A. S. S. de.; SANTOS, A. G.; FONTES, G. G. dos S. A importância da formação inicial e continuada do professor para o uso das TIC em sua prática pedagógica: um olhar sobre o ensino da matemática em Aracaju-SE. $9^{0}$ Encontro Internacional de Formação de Professores e 10 Fórum Permanente de Inovação Educacional, 2016, Universidade de Tiradentes, Farolândia, Aracaju, 2016.

SCHNEIDER, D. da R. Prática dialógico-problematizadora dos tutores na UAB/UFSM: fluência tecnológica no Moodle. Dissertação (Mestrado em educação), Universidade Federal de Santa Maria, Santa Maria, 2012, 204 p.

SCHEIBE, L.; AGUIAR, M. A. Formação de profissionais da Educação no Brasil: O curso de pedagogia em questão. Educação \& Sociedade. Ano XX, nº 68. Dezembro de 1999.

SONEGO, A. H. S. A integração das tecnologias educacionais em rede e a convergência entre as modalidades no processo ensino-aprendizagem. Dissertação (Mestrado em educação), Universidade Federal de Santa Maria, Santa Maria, 2014, 257p.

SOUZA, Â. R. A política educacional e seus objetos de estudo. Revista de Estudios Teóricos y Epistemológicos en Política Educativa, v. 1, n. 1, p. 75-89, 2016. 